\title{
Grit utility in explaining job and contextual performance
}

\author{
Steluța Peleașă
}

Parenting Romania

\section{ARTICLE INFO}

Article history:

Received 14-April-2018

Accepted 20-August-2018

Available online 01-October-2018

This article should be cited as: Peleașă, S., (2018). Grit utility in explaining job and contextual performance. Studia Doctoralia. Psychology and Educational Science, 15, 54-64.

This is an open access article under the CC BY license (http://creativecommons.org/licenses/by/4.0/).

Corresponding author at: Parenting Romania, Department of Social Programs, Psyence, Romania, Icoanei Street, no 6A, Bucharest, RO.

E-mail address: steluta.peleasa@psyence.ro

\section{ABSTRACT}

The study aims to analyze if grit brings incremental validity in the prediction of job performance criteria (task performance, organizational citizenship behaviors and counterproductive work behaviors), in addition to some classical predictors such as emotional intelligence and some personality factors (conscientiousness and agreeableness). The sample consists of 170 employees from various fields of activity. Regression analysis has shown that grit has no incremental validity to personality and emotional intelligence in predicting any of the work performance criteria (task performance, organizational citizenship behaviors and counterproductive work behaviors). The study therefore brings to the academic literature one more proof for the fact that it is difficult to consider grit an independent, self-constructed concept.

Keywords: grit, emotional intelligence, personality (conscientiousness, agreeability), work performance (task performance, organizational citizenship behaviors and counterproductive work behaviors).

\section{INTRODUCTION}

The study aims to analyze if grit brings incremental validity in the prediction of job performance criteria (task performance in performance, organizational citizenship behaviors and counterproductive work behaviors), in addition to some classical predictors such as emotional intelligence and some personality factors (conscientiousness and agreeableness).

Research regarding job performance (JP) has gone a long way and has made substantial progress. The most important achievements are certainly the differentiation between task performance (TP) and contextual performance (CP) (Borman, 1993), differentiation between different CP constructs, with particular emphasis on proactive performance, new perspectives on the dynamic character of performance, as well as the understanding of performance predictors, especially person-specific predictors. Numerous studies were conducted, resulting in a solid knowledge base. The major interest was focused on studying three types of 
performance: TP, organizational citizenship behavior (OCB) and counterproductive work behavior (CWB).

TP is the contribution of a person to organization's performance, refering to actions included in the formal reward system (related to technical aspects) and addressing the requirements specified in job descriptions (Williams and Karau, 1991). Generally speaking, TP consists of activities that transform raw materials into goods and services produced by the organization, or allow the organization to function effectively (Motowidlo et al., 1997). Thus TP refers to the fulfillment of the requirements that are part of the employee - employer contract.

It is often unsatisfactory for employees to comply only with formal job requirements, being necessary to take action beyond what is formally needed (Parker et al, 2006; Sonnentag and Frese, 2002).

Organizational citizenship behavior (OCB) describes an arbitrary behavior that is not necessarily recognized and rewarded by the formal reward system. Arbitrary behavior means that it is not mandatory and is not formally included in the employee - employer contract, for example, to help a colleague, to work overtime when necessary. Moreover, Organ (1988) explains that any minor OCB example is not expected to make a visible difference in the organization's results, but the aggregate actions promote the efficient functioning of an organization (Organ, 1988; 1997). The OCB has thus been theorized from two relevant perspectives: OCB as extra-role behavior and OCB as civility (Fieldspe, 2001).

Counterproductive work behaviors (CWB) are extrarole behaviors that harm individuals and organizations. CWB are studied by different researchers using various names. An analysis made by Sulea (2008) shows that CWB are being studied as "employee deviance", "antisocial behaviors", "dysfunctional workplace behaviors," "inappropriate interpersonal actions", "social undermining", "incivility", "abusive leadership", "emotional abuse", "sabotage", "aggression", and a few others. The range of these behaviors is therefore very diverse, but in this context it is often related with: stealing, absenteeism, verbal abuse of clients or colleagues, use of substances (alcohol or drugs), sabotage of production or property, delay, indolence, unauthorized medical leave etc.

In relation to these three types of performance, the predictive power of several variables was tested, focusing mainly on the following concepts as predictive factors: intelligence and personality factors (Schmidt \& Hunter, 1998). For these classical predictors, although having sizable correlations, for example with JP, the magnitude of these correlations is rather not significant (intelligence, $r=$ .56 , according to a meta-analysis conducted by Hunter and
Schmidt, 1998, and conscientiousness, $r=.26$, according to Judge, Keller and Mount, 2002) and scientific studies admit that there are considerable limitations in identifying and analyzing factors that predict individual performance (Schmidt \& Hunter, 1998). Cumulative models account for a maximum of $50 \%$ of the performance variance, of which the main prediction is the IQ (about 30\%,r $r=.56$ ) (Schmidt \& Hunter, 1998). A huge proportion, therefore, remains unexplained, and scientific research promotes the investigation of a variety of constructs that can explain individual differences in performance, whether reffering to academic or professional performance.

The topic of study for the current research is to investigate a relatively new concept: GRIT. Angela Duckworth is the author who proposed and promoted this concept, considering that in order to understand how the study of grit evolved, it is necessary to return in time, more precisely until 1907, when William James proposed to set up a "study program which could cover the entire area of psychology". James encouraged psychologists to address two major issues: first - what are the human abilities and the second - by what means individuals valorize their abilities. Angela Duckworth believes that psychology has made an impressive progress since James's suggestion by providing answers primarily to the first of two questions. With all the solid debates on the dimension and origin of intelligence, the knowledge about IQ has developed more than for any other individual difference - by measuring IQ with a solid reliability and validity and by testing for what IQ is a good predictor. But, as James claims (1907), we know less about the reason why some individuals use only a small part of their personal resources while some exceptional individuals push their boundaries. In the article where the concept of "grit" begins, the author reiterates James's second question in the following terms: "Why do some people achieve more than others with the same intelligence?" (Duckworth et al., 2007). In addition to cognitive skills, a list of attributes of highachieving individuals would include: creativity, strength, emotional intelligence, charisma, self-confidence, affective stability, physical attractiveness, and other positive qualities. Priori, some features seem more important than others for particular careers. Extraversion can be fundamental to a career in sales, for example, but irrelevant for a creative writing career. However, some features could be key to success regardless of the field. The author considers that a personal quality is present at the most prominent leaders in any field: grit.

She defines grit as "perseverance and passion for longterm goals" (Duckworth, 2007). Grit involves intense work to achieve goals and to maintain effort and interest for years despite failures, adversities and monotony. Individuals with grit approach a task as a long athletic race, their advantage being resistance. While disappointment or boredom are 
signs for others that it is time to change the path or resign, the individuals with high grit maintain the initial course. The author's hypothesis that grit is essential for high achievements has emerged during discussions with professionals in the banking, painting, journalism, academic, medical and legal fields. It has emerged from these discussions that people who do not seem to be intellectually endowed like others have achieved certain achievements through sustained commitment, and others who at first sight seem to have superior general mental skills did not reach the upper level in their field of activity (Duckworth et al., 2007).

The major interest in studying the factors that influence work performance makes the grit a relatively new concept and very fashionable nowadays, which is why more exploratory research is needed to determine its exact role alongside the classical factors studied so far. Thus, a clear first question in the critical analysis of the concept would be: "How could this concept have been ignored for 100 years?" The obvious answer is that it was not ignored, but being integrated within the personality dimensions (of the predominant psychology today, namely Big Five) under the name "conscientiousness". Thus, it is a matter of conceptual differences, but also of measurement, when reffering to grit and conscientiousness. A second question is related to the actual usefulness of the concept of grit. More specifically, in order to be useful in psychology, a concept must be measurable but also relevant from an applicative point of view.

The present research aims to analyze the incremental value of the grit in addition to the other non-cognitive predictors in predicting JP by influencing the three main types of performance: TP (task performance), OCB (organizational citizenship behaviour) and CWB (counterproductive work behavior).

\section{Noncognitive Predictors of Task and Contextual Performance}

\section{Personality}

Personality traits are important for the functioning of individuals at work because cognitions, emotions and behaviors reflected in personality are considered to contribute not only to the task accomplishment (Barrick, Mount and Judge, 2001), but also to how individuals react and relate while working together (LePine, Buckman, Crawford, \& Methot, 2011; LePine \& Van Dyne, 2001). While conscientiousness has proven to be a good predictor for work performance (Barrick \& Mount, 1991), agreeability proved to be particularly relevant to social interactions (McCrae \& Costa, 1989; Wiggins \& Trobst, 1999). Extraversion is a good predictor for task performance in specific contexts, e.g., in sales. Openness to experience is a good predictor of training efficiency and is less relevant for task performance, because people with high scores in this dimension are characterized by a positive attitude towards the learning experience in general. Following their metaanalysis, Barrick and Mount (Barrick \& Mount, 1991) concluded that neuroticism had little correlation with the tracked variables - task performance, training efficiency and staffing (personnel data - salary level, job changing frequency, statut, etc.).

Therefore, in the present paper the focus will be on those two factors (Conscientiousness and Agreeableness) that seem to have the strongest links to the types of performance we are studying.

\section{Conscientiousness}

$C$ is considered the most valid personality predictor for work performance (Behling, 1998; Mount \& Barrick, 1998, cit., Dudley et al., 2006). In fact, empirical research has shown $\mathrm{C}$ to be positive corelated with performance based on various task performance criteria from many professional fields (Barrick \& Mount, 1991, Salgado, 1997, cit. Dudley et al. 2006). Hurtz and Donovan (2000, Dudley et al., 2006) had estimated in a meta-analysis that the corrected average of the criterion validity for the relationship between $C$ and worldwide task performance in the workplace is 0.22 . In terms of organizational civic behavior (OCB), a 2011 metaanalysis of 743 articles shows for the $C$ effect on OCB a corrected meta-analytical index of $\rho=.18$ (Chiaburu et al., 2011).

\section{Agreeableness}

Agreeableness $(A)$ is a personality trait manifested in individual behavioral characteristics as being sympathetic, cooperative, warm and caring (Thompson, 2008). In the psychology of contemporary personality, $A$ is one of the five major dimensions of the personality structure, reflecting the individual differences in cooperation and social harmony (Graziano, Hogan, 1997).

Because $A$ is a social feature, research has shown that agreeableness of an individual has a positive correlation with the quality of relationships with the team members he is part of. Also, it positively predicts transformational leadership skills.

\section{Emotional intelligence}

The emotional intelligence (EQ) construct has been trying for a good time to gain a distinct place in psychology. Although there are many models and implicitly possible definitions of the term Emotional Intelligence, the most widely accepted definition today is that offered by Mayer, Salovey and Caruso (2000, p. 396): "the ability to perceive and express emotions, assimilate emotion in thought, 
understand and reason with emotion and regulate emotion in the self and others."

Through the Mayer-Salovey-Carouso Emotional Intelligence Test (MSCEIT, Mayer, Salovey and Caruso, 2002), the measured emotional intelligence construct correlates modestly with two of the Big Five personality traits (rs <.24 for agreeableness and openness to experiences), recording a correlation index $r=.35$ with the SAT verbal abilities test. Also, the emotional intelligence measured by MSCEIT also adds incremental validity over the predictions that can be made based on personality traits and verbal abilities (Brackett, Mayer and Warner, 2003).

In the meta-analysis conducted in 2010, Joseph and Newman argue that "in the organizational environment, emotion regulation is theoretically related to work performance by generating a beneficial affective state for performance." The regulation of emotions is therefore "the tool through which we create and preserve positive emotional states that are beneficial to work behaviors" (George, 1991). Tsai, Chen and Liu (2007) have developed a model of relationships between positive states and work performance: positive states indirectly predict performance through interpersonal processes - helping colleagues and receiving their support. Therefore, we can expect people with high emotional intelligence to manage their emotional regulation processes more effectively, to induce and support a positive affective state, which in turn will generate supportive behavior and motivation reflected, ultimately, in work performance.

In conclusion, when we talk about EQ in the work context, we can expect that people with high EQ scores to show altruism, compliance and politeness, behaviors for the benefit of their colleagues, and ultimately for the whole organization (Joseph \& Newman, 2010). The studies of Carmeli (2003), Carmeli \& Josman (2006), Lopes et. al. (2006), argue that EQ is an important predictor for civicorganizational behaviors.

\section{Grit in relation with non-cognitive performance predictors}

The first mention of the concept of grit as a distinct psychological variable was in 2007 (Duckworth et al., 2007), where it was proposed as a concept related to conscientiousness (as a dimension of the Big Five personality model), but having certain distinctions from it. Conscientious individuals are typically meticulous, attentive, trustworthy, well-organized, diligent and calm. Although all these qualities make a plausible contribution to personal achievements, their relative importance varies according to the proposed goal. For example, Galton (1892, Duckworth et al., 2007) suggested that self-control (the ability to resist temptations and impulse control) is a surprisingly poor predictor for achieving the highest goals. In accordance with Galton, also Hough (1992, Duckworth et al., 2007) distinguishes between the facets of conscientiousness. According to Hough, goal-oriented people are those who work hard, try to do the right thing, and perform tasks easily, while people with the sense of duty are controlled and conventional. Hough (1992, cit. Duckworth et al., 2007) has found in a meta-analysis measurement scales that show that goal orientation is a better predictor of work efficiency ( $r=$ $.15)$ and educational success $(r=.29)$ than the sense of duty $(r=.08$ and $r=.12$ respectively).

Grit partly overlaps with the need for achievement (as a facet of conscientiousness) but differs by placing emphasis on the long-term effort rather than on the short-term intensity. Individuals with grit not only easily complete tasks but they can pursue a goal for many years. Grit is also distinct from the sense of duty (as a facet of conscientiousness) which includes self-control in terms of goals and interests. A person with much self-control but less grit could, for example, maintain temper, persevere in a diet, resist the impulse to surf the Internet at work, and yet change his annual job. As Galton suggested (1892, Duckworth et al., 2007), a lasting commitment to a particular vocation does not derive from resistance to frequent temptations.

Also, grit differs from the need for achievement described by McClelland as a race to complete easy-toachieve goals and providing immediate feedback on execution (1961, Duckworth et al., 2007). While individuals with a strong need for achievement pursue goals that are neither too difficult nor too easy to achieve, high-grit individuals are deliberately setting for themselves extremely long-term goals and not deviate from them even in the absence of positive feedback.

The second important distinction is that the need for achievement is, by definition, an unconscious orientation toward the implicitly rewarded activities and, therefore, impossible to measure by self-assessment methods (McClelland, Koestner \& Weinberger, 1992). In contrast, grit implies dedication for rewarded goals, either implicitly or explicitly. In addition, the authors see no reason why individuals would not be aware of their grit level.

A reference research was carried out by Rimfeld et al. (2016) and it is the most extensive study on grit so far. Running in the UK on 4,642 16-year-old twins, the study revealed that grit (measured by the Grit-S scale - as persistence in effort and consistency of interests) and the Consciousness from Big Five are to a large extent the same trait, both phenotype $(r=.53)$ and genetic (genetic correlation $r=.86$ ). Personality significantly predict academic results, but grit adds very little to the prediction of 
academic achievements beyond IQ and traditional personality factors, especially conscientiousness.

In the light of previously mentioned results from studies of Rimfeld et al. (2016), there is little evidence for grit as a stand-alone concept apart from personality, and even less evidence of its criterion validity in relation to academic or work results.

The lack of robust, extensive research for grit analysis in work context is the reason why the following hypotheses were chosen to be examined in this study:

H1: Grit has incremental validity over personality factors (conscientiousness and agreeableness) in predicting organizational civic behavior (OCB).

$\mathrm{H} 2$ : Grit has incremental validity over personality factors (conscientiousness and agreeableness) in predicting counterproductive work behavior (CBW).

H3: Grit has incremental validity over personality factors (conscientiousness and agreeableness) in prediction of task performance $(T P)$.

To assess the usefulness of grit as a concept, other authors also tested its relationship with conscientiousness, but also with emotional intelligence. In a study of 2014, conscientiousness, grit and emotion management variables (a component of emotional intelligence in the MayerSalovey-Caruso paradigm) were tested as predictors of various school-related outcomes, such as deviation from rules (measured on a scale of 1 to 407, varying on violation of rules such as delay, lack of homework, refusal to work on projects, etc.), school recognition (measured by diplomas

\section{METHODOLOGY}

\section{Sample and procedure}

The sample of the research consisted of 170 adults aged between 22 and $60(\mathrm{~m}=35.82$ and $\mathrm{SD}=7.13)$ who currently are employed. Women were the majority (representing $71 \%$ of the total). It was a convenience sample. The questionnaires have been applied online, the eligibility criterion for inclusion in the study being that participants are currently holding a job. Instructions for each scale were presented before items. Responses were processed in Microsoft Excel and subsequently in SPSS.

\section{Instruments}

In order to achieve the proposed research goals, the following psychological tools were used:

Grit. The "grit scale" questionnaire was first validated in 2007 by Duckworth et al., and has 12 items divided into two obtained after teachers' assessments 6 times per year for work ethic and civic factors), academic prizes (from the end of quarter), total academic score (GPA) and school satisfaction. The results showed that $C$ correlates with grit and emotions management, but grit did not correlate with emotions management, nor did it bring anything further as incremental validity to any targeted criteria (Ivcevic, Brackett, 2014). This study aimed to question the validity of three predictors for school outcomes - conscientiousness, grit and Emotion Regulation Ability (ERA - a component of emotional intelligence in the Mayer-Salovey-Caruso paradigm aiming maximum performance achievement based on emotional ability for problem solving). Regression analyses showed that school outcomes were significantly predicted by $C$ and ERA, and grit had a non-significant influence.

Considering that these criteria can be considered as being school equivalent of job-related criteria such as task performance, contextual performance and job satisfaction, the usefulness of grit as a concept became questionable in Industrial-Organizational Psychology. The following assumptions were questioned:

14: Grit has incremental validity over emotional intelligence in predicting organizational civic behavior (OCB).

15: Grit has incremental validity over emotional intelligence in predicting counterproductive work behavior (CWB).

16: Grit has incremental validity over emotional intelligence in prediction of task performance (TP).

sub-scales: consistency of interest and persistence in effort, with 6 items each (Duckworth et al., 2007) on a 5-step Likert scale. The full scale score was used for this study. Example of item: "Failures do not discourage me". The internal consistency index estimated for a sample of 1218 subjects was $\alpha=.79$ (Duckworth et al., 2007).

Task Performance. TP was measured using a self-report questionnaire, whereby the employees were urged to selfassess their job performance using 5 items on a 5 -step Likert scale. This type of measurement was used because the sample included persons from different companies and work fields.

Organizational Citizenship Behavior. For the OCB evaluation, a scale developed by Williams and Anderson was used, comprising 13 items on two subscales: OCBI and OCBO, with 7 and 6 items respectively (Williams, Anderson, 
1991). Items such as "I reserve time to listen the problems and concerns of my colleagues" have been used for measuring $\mathrm{OCB}$.

Counterproductive work behavior. For the CWB evaluation, a selection of 10 items from the CWB-C scale ("Counterproductive Work Behavior - Checklist") was used, developed by Spector et al. (2006). The scale includes 45 items, divided into two subscales: CWB related to the organization (eg items: "I stayed home instead of going to work and I said I was sick although I was not.") and CWB related to people (eg items:" I started a quarrel with someone at work.").

Emotional intelligence. MSCEIT test was used for EQ measurement, applied online using www.testcentral.ro

\section{RESULTS}

A preliminary correlation was made to determine the associations between TP, OCB, CWB and the proposed predictors: grit, emotional intelligence conscientiousness and agreeableness as personality facets of Big Five model. Grit was significantly correlated with task performance $(r=$ $.28, p<0.01)$, organizational citinzenship behavior $(r=.32$, $p<0.01)$, agreeableness $(r=.28, p<0.01)$ and conscientiousness ( $r=.59, p$ 0.01). As can be seen, grit has platform. The test contains 141 items on 4 sub-scales: emotion perception, facilitating thinking, understanding emotions and managing emotions. MSCEIT is an aptitudes scale, measuring how well people perform tasks and solve emotional problems. The test items are based on daily life scenarios, being built in the tradition of intelligence testing, as an aptitude test with correct or wrong answers.

Personality. The NEO-FFI test (short form of the NEO PI-R test) was used to measure personality facets, applied online using www.testcentral.ro platform. The test includes 60 items on 5 sub-scales, corresponding to the Big Five personality model: neuroticism, agreeableness, extraversion, openness to experience and conscientiousness, thus allowing a comprehensive assessment of the adult personality.

been positively correlated with all the criteria covered by this research. The size of the correlation between grit and conscientiousness brings a new empirical evidence to the argument that grit is a part of conscientiousness or at least in part, overlaps with it. The personality facets, $A$ and $C$ also correlated with targeted criteria. Emotional intelligence also correlated with TP, but did not correlate with OCB, grit and conscientiousness. Table 1 reflects these data.

Table 1 Descriptive statistics

\begin{tabular}{|c|c|c|c|c|c|c|c|c|c|}
\hline & $\mathrm{M}$ & SD & 1 & 2 & 3 & 4 & 5 & 6 & 7 \\
\hline 1. Task Performance (TP) & 31.72 & 2.88 & - & & & & & & \\
\hline 2. Organizational Citizenship Behavior (OCB) & 54.89 & 5.88 & $.47^{\star \star}$ & - & & & & & \\
\hline 3. Counterproductive work behavior (CWB) & 15.62 & 3.63 & $-.30^{\star *}$ & $-.34^{* *}$ & - & & & & \\
\hline 4. Grit & 42.27 & 5.25 & $.28^{\star \star}$ & $.32^{\star \star}$ & $-.20^{*}$ & - & & & \\
\hline 5. Agreeableness $(A)$ & 43.49 & 5.33 & $.32^{\star \star}$ & $.37^{\star \star}$ & $-.29 *$ & $.28^{\star *}$ & - & & \\
\hline 6. Conscientiousness (C) & 48.92 & 5.93 & $.41^{\star \star}$ & $.31^{\star \star}$ & $-.24^{\star \star}$ & $.59 \star \star$ & $.43^{\star \star}$ & - & \\
\hline 7. Emotional intelligence (EI) & 0.44 & 0.04 & $.24^{\star *}$ & .11 & -.12 & .06 & .12 & .05 & - \\
\hline
\end{tabular}

A 3-step regression analysis was performed to test the assumptions about grit's incremental validity. In order to verify the hypotheses $I 1, I 2$ and $I 3$, personality facets ( $A$ and C) were entered in step 2 and grit in step 3 , for each type of performance (TP, OCB, CWB). To verify the hypotheses 14 , 15 and 16 , emotional intelligence was introduced in step 2 and grit in step 3, for each type of performance (TP, OCB, CWB). Table 2 reflects the results of these analyses. 


\begin{tabular}{|c|c|c|c|c|c|c|}
\hline $11,12,13$ & TP & & CWB & & OCB & \\
\hline & $B$ & $\Delta \mathrm{R}^{2}$ & $B$ & $\Delta \mathrm{R}^{2}$ & $B$ & $\Delta \mathrm{R}^{2}$ \\
\hline Step 1 & & .02 & & -.008 & & .02 \\
\hline Gender & .29 & & .01 & & .21 & \\
\hline Age & .01 & & -.01 & & .02 & \\
\hline Step 2 & & .17 & & .09 & & .14 \\
\hline Gender & .22 & & .06 & & .14 & \\
\hline Age & .004 & & -.004 & & .01 & \\
\hline Agreeableness & .17 & & -.23 & & .29 & \\
\hline Conscientiousness & .33 & & -.14 & & .17 & \\
\hline Step 3 & & -.003 & & -.002 & & .02 \\
\hline Gender & .23 & & .05 & & .17 & \\
\hline Age & .003 & & -.002 & & .01 & \\
\hline Agreeableness & .17 & & -.23 & & .28 & \\
\hline Conscientiousness & .29 & & -.09 & & .66 & \\
\hline Grit & .06 & & -.08 & & .19 & \\
\hline Final model & & $\mathrm{R}^{2}=.18$ & & $\mathrm{R}^{2}=.08$ & & $\mathrm{R}^{2}=.18$ \\
\hline $14,15,16$ & $\mathrm{TP}$ & & CWB & & OCB & \\
\hline & $B$ & $\Delta R^{2}$ & $B$ & $\Delta R^{2}$ & $B$ & $\Delta \mathrm{R}^{2}$ \\
\hline Step 1 & & .02 & & -.008 & & .02 \\
\hline Gender & .29 & & .01 & & .21 & \\
\hline Age & .01 & & -.01 & & .02 & \\
\hline Step 2 & & .05 & & .008 & & .008 \\
\hline Gender & .27 & & .02 & & .19 & \\
\hline Age & .014 & & -.01 & & .02 & \\
\hline Emotional intelligence & .24 & & -.12 & & .12 & \\
\hline Step 3 & & .06 & & .027 & & .08 \\
\hline Gender & .29 & & -.001 & & .23 & \\
\hline Age & .004 & & -.003 & & .01 & \\
\hline Emotional intelligence & .22 & & -.104 & & .09 & \\
\hline Grit & .27 & & -.19 & & .30 & \\
\hline Final model & & $\mathrm{R}^{2}=.13$ & & $\mathrm{R}^{2}=.03$ & & $\mathrm{R}^{2}=.11$ \\
\hline
\end{tabular}

\section{DISCUSSION}

The results of the first three hypotheses prove that grit brings no incremental value over personality factors ( $A$ and $C$ ) in the prediction of any of the three performance criteria (TP, $\mathrm{OCB}$ and $\mathrm{CWB}$ ). Thus further clarifications are needed to determine if grit is a concept with its own identity in relation to $\mathrm{C}$. This will therefore be a proposal for future research directions.
Regarding the other three hypotheses, given the claim of the mass-media that grit is the differentiating ingredient of success and achievements that stands the test of time, the fact that grit does not have incremental value over $\mathrm{EQ}$ in the prediction of the three types of performance is quite a surprising result, which we did not anticipate. If there was a significant increase, then the proposed direction of research 
would be the hypothesis that grit is a performance predictor outside the personality area, finding a relevant place in cumulative models designed to explain performance prediction.

Another surprising result is the lack of correlations between emotional intelligence and contextual performance, and between grit and personality factors ( $A$ and $C$ ). It turned out that only task performance correlates with emotional intelligence. Given that we do not know the specifics of the areas in which the respondents work (whether jobs involve predominantly technical activities or either a high degree of human interaction), we can not draw a relevant conclusion regarding the relationships between those characteristics that represent us as individuals and the behaviors that we choose to manifest in work context. And especially because is a matter of subjective perception when assessing contextual performance, OCB or CWB.

\section{Limitations}

A first limit of this study could be the disproportion between male and female respondents. The relatively small number of respondents, the fact that the persons included in this research come from a variety of industries, without knowing the specifics of the domains in which they perform and the fact that the location of the respondents is mainly in Bucharest, also constitute limitations on the representativeness of the sample considered for this study.

The use of self-report questionnaires is also a limitation of this study, especially when it comes to measuring performance, given that a supervisor or an evaluation system based on objective measurement - with relevant performance indicators, may present different values from those perceived and reported by the employee. Also, the fact that the most important predictor of performance, namely intelligence, was not taken into account in the research, the results regarding the predictive degree of emotional intelligence and personality can not be considered robust and fully relevant.

\section{REFERENCES}

Barnard, C. I. (1938). The Functions of the Executive. Cambridge, MA: Harvard University Press.

Bateman, T. S., \& Organ, D. W. (1983). Job satisfaction and the good soldier: The relationship between affect and employee "citizenship." Academy of Management Journal, 26(4), 587-595.
Another limit can be the lack of a specialized literature on grit subject (especially in relation to the constructs concerned), which prevents a clear conceptual classification and a generalization of the present results.

\section{Further Directions}

Being a fashionable, highly popular concept in recent years, robust research is required for a more clear positioning compared to other constructs (to what extent it differentiates or is equivalent to the Perseverance subscale of $C$ ) and at the same time the magnitude of the influence this construct has as a predictor of work performance.

A hypothesis that must be verified and argued or counterargued on the basis of scientific studies is the idea which is strongly promoted in the media that cognitive abilities are not the ones that help the most in achieving performance (academic or professional), but it is the grit that differentiates between top performers.

The same trend of being a fashionable concept that seemed to be the differentiating factor for achieving success in life was also in the case of EQ. Only scientific research could clarify that classical performance predictors (GMA and personality factors) undoubtedly have the lead role and the incremental value of $E Q$ is insignificant. The same research directions must also be followed in the case of grit: on one hand, to clarify to what extent is a self-contained concept outside the personality area or as an integrated part of the personality traits (different or not compared to conscientiousness); the research directions may also aim to clarify whether grit is a relevant predictor of performance and to measure the magnitude of its relationship with JP (what incremental value brings in performance prediction in addition to cognitive skills and personality traits); and if it proves that grit does not have a direct impact on performance, then it should be explored if it has a moderator role, which may be the puzzle piece that can moderate other relevant predictors for performance. Therefore, grit may act 'behind the scenes', being a catalyst or a hindrance for achieving and / or maintaining performance over time.

Bennett, R. J., \& Robinson, S. L. (2000). Development of a Measure of Workplace Deviance. Journal of Applied Psychology, 85, 349-360.

Borman, W. C., \& Brush, D. H. (1993). More Progress Toward a Taxonomy of Managerial Performance Requirements. Human Performance, 6(1), 1-21.

Borman, W. C., \& Motowidlo, S. J. 1997. Task performance and contextual performance: The meaning for personnel selection research. Human Performance, 10: $99-109$. 
Borman, W. C., \& Motowidlo, S. J. 1993. Expanding the criterion domain to include elements of contextual performance. In N. Schmitt, W. C. Borman, \& Associates (Eds.), Personnel selection in organizations: 71-98. San Francisco, CA: Jossey-Bass.

Brackett, M., \& Mayer, J. D. (2003). Convergent, Discriminant, and Incremental Validity of Competing Measures of Emotional Intelligence. Personality and social psychology bulletin, 29(9), 1147-1158.

Brief, A. P., \& Motowidlo, S. J. (1986). Prosocial organizational behaviors. Academy of Management Review, 11, 710-725.

Campbell, J. P. (1990). Modeling the performance prediction problem in industrial and organizational psychology. In M. D. Dunnette \& L. M. Hough (Eds.), Handbook of Industrial and Organizational Psychology. Palo Alto, CA: Consulting Psychologists Press, Inc.

Campbell, J. P., McCloy, R. A., Oppler, S. H., \& Sager, C. E. (1993). A theory of performance. In N. Schmitt \& W. C. Borman (Eds.), Personnel selection in organizations (pp. 35-70). San Francisco: Jossey-Bass.

Carter, N. L., Guan, L., Maples, J. L., Williamson, R. L., \& Miller, J. D. (2015). The downsides of extreme conscientiousness for psychological wellbeing: The role of obsessive compulsive tendencies. Journal of Personality.

Chen, P., Spector, P.E. (1992). Relationship of work stressors with aggression, withdrawal, theft and substance use: An exploratory study. Journal of Occupational and Organizational Psychology, 65, 177184.

Chiaburu, D. S., Oh, I.-S., Berry, C., Li, N., \& Gardner, R. G. (2011). The Five-Factor Model of Personality Traits and Organizational Citizenship Behaviors: A MetaAnalysis. Journal of Applied Psychology, 96(6), 11401166.

Colquitt, J. A. (2001). On the Dimensionality of Organizational Justice: A Construct Validation of a Measure. Journal of Applied Psychology, 86 (3), p. 386400.

Costa, P. T. \& McCrae, R. R. (1992). NEO personality Inventory professional manual. Odessa, FL: Psychological Assessment Resources.
Costa, P. T. Jr., \& McCrae, R. R. (1985). The NEO Personality Inventory Manual. Odessa, FL: Psychological Assessment Resources, Inc.

Costa, P. T., \& McCrae, R. R. (1976). Age differences in personality structure: A cluster analytic approach. Journal of Gerontology 31 (5): 564-570.

Costa, P. T., \& McCrae, R. R. (1992). Revised NEO Personality Inventory (NEO PI-R) and the NEO FiveFactor Inventory (NEO-FFI) Professional Manual. Odessa, FL: Psychological Assessment Resources.

Crant, J. M. (1995). The Proactive Personality Scale and objective job performance among real estate agents. Journal of Applied Psychology, 80, 532-537.

DeYoung, C., Peterson, J., \& Higgins, D. (2002). Higherorder factors of the Big Five predict conformity: Are there neuroses of health? Personality and Individual Differences, 33, 533-552.

Douglas, S. C., \& Martinko, M. J. (2001, September). Exploring the Role of Individual Differences in the Prediction of Workplace Aggression. Journal of Applied Psychology, 86(4):547-59.

Duckworth, A. L., Peterson, C., Matthews, M. D., \& Kelly, D. R. (2007). Grit: Perseverance and passion for longterm goals. Journal of Personality and Social Psychology, 9(1087-1101).

Dudley, N. M., Orvis, K. A., Lebiecki, J. E., \& Cortina, J. M. (2006). A Meta-Analytic Investigation of Conscientiousness in the Prediction of Job Performance: Examining the Intercorrelations and the Incremental Validity of Narrow Traits. Journal of Applied Psychology, 91(1), 40-57.

Fox, S., Spector, P.E. (1999). A model of work frustrationaggression. Journal of Organizational Behavior, 20, 915931.

Fox, S., Spector, P.E., Miles, D. (2001). Counterproductive Work Behavior (CWB) in Response to Job Stressors and Organizational Justice: Some Mediator and Moderator Tests for Autonomy and Emotions. Journal of Vocational Behavior, 59, 291-309.

Frank L. Schmidt, J. E. Hunter (1998). The Validity and Utility of Selection Methods in Personnel Psychology: Practical and Theoretical Implications of 85 Years of Research Findings. Psychological Bulletin, American Psychological Association, (Vol. 124, No. 2) pp. 262-274. 
Galperin, B. (2002). Determinants of deviance in the workplace. Teză doctorală nepublicată.

George, J. M., \& Brief, A. P. 1992. Feeling good-doing good: A conceptual analysis of the mood at workorganizational spontaneity relationship. Psychological Bulletin, 112: 310 -329.

George, J. M. 1990. Personality, affect, and behavior in groups. Journal of Applied Psychology, 75: 107-116.

George, J. M. 1991. State or trait: Effects of positive mood on prosocial behavior at work. Journal of Applied Psychology, 76: 299 -307.

George, J. M., \& Bettenhausen, K. 1990. Understanding prosocial behavior, sales performance, and turnover: A group-level analysis in a service context. Journal of Applied Psychology, 75: 698 -709.

George, J. M., \& Jones, G. R. 1997. Organizational spontaneity in context. Human Performance, 10: 153170.

Graziano W.G.; Bruce J. W.; Sheese B.E.; Tobin R.M. (2007). "Attraction, personality and prejudice: Liking none of the people most of the time". Journal of Personality \& Social Psychology 93: 565-582.

Graziano, W.G., \& Eisenberg, N. (1997). Agreeableness; A dimension of personality. In R. Hogan, S. Briggs, \& J. Johnson, (1997). Handbook of Personality Psychology. San Diego, CA: Academic Press.

lliescu, D., \& Ticulescu, L. (2014). Training APIO (Asociația de Psihologie Industrială și Organizațională). Retrieved from Diagnoza organizationala (nivel introductiv): http://training.apio.ro/

Ivcevic, Z., \& Brackett, M. (2014). Predicting school success: Comparing Conscientiousness, Grit, and Emotion Regulation Ability. Journal of Research in Personality, 52, 29-36.

John, O. P., Naumann, L. P., \& Soto, C. J. (2008). Paradigm Shift to the Integrative Big-FiveTrait Taxonomy: History, Measurement, and Conceptual Issues. In O. P. John \& R. W. P. Robins, La As (Eds.), Handbook of personality: Theory and research (pp. 114-158). New York, NY: Guilford Press.

Katz D., \& Kahn R. L. (1966). The social psychology of organizations. New York: Wiley. p 489.
Katz, D. (1964). The motivational basis of organizational behavior. Behavioral Science 9: 131-133.

Laursen B.; Pulkkinen L.; Adams R. (2002). The antecedents and correlates of agreeableness in adulthood. Journal of Developmental Psychology 38(4): 591-603.

Lepine, J. A., Erez, A., \& Johnson, D. E. (2002). The nature and dimensionality of organizational citizenship behavior: a critical review and meta-analysis. Journal of Applied Psychology, 87(1), 52-65.

Matsumoto, D., \& Juang, L. (2012). Culture and Psychology: 5th Edition. Belmont, CA: WadsworthCengage Learning. p. 271.

Mayer, J. D., \& Salovey, P. (1997). What is emotional intelligence? In P. Salovey \& D. Sluyer (Eds.), Emotional development and emotional intelligence: Implications for educators (pp. 3-31). New York: Basic Boks.

Mayer, J. D., Roberts, R. D., \& Basarde, S. G. (2008). Human abilities: Emotional intelligence. Annual Review of Psychology, 59, 507-536.

Mayer, J. D., Salovey, P., Caruso, D. L., \& Sitarenios, G. (2001). Emotional intelligence as a standard intelligence. Emotion, 1, 232-242, 396.

Morrison, E. W., \& Phelps, C. C. 1999. Taking charge at work: Extrarole efforts to initiate workplace change. Academy of Management Journal, 42: 403-419.

Motowidlo, S. J., \& Van Scotter, J. R. 1994. Evidence that task performance should be distinguished from contextual performance. Journal of Applied Psychology, 79: $475-480$

Motowildo, S. J., Walter, C. B., \& Schmit, M. J. (1997). A Theory of Individual Differences in Task and Contextual Performance. Human Performance, 10(2), 71-83.

O'Reilly, C., \& Chatman, J. 1986. Organizational commitment and psychological attachment: The effects of compliance, identification and internalization on prosocial behavior. Journal of Applied Psychology, 71: 492- 499.

Organ, D. W. (1988). Organizational Citizenship behavior: The good soldier syndrome. Lexington, MA: Lexington Books. 
Ozer, D. J., \& Benet-Martínez, V. (2006). Personality and the prediction of consequential outcomes. Annual Review of Psychology, 57, 401-421.

Pearson, C. M., \& Porath, C. L. (2005). On the nature, consequences and remedies of workplace incivility: No time for "nice"? Think again. Academy of Management Executive, Vol. 19., No.1

Penney, L.M., Spector, P.E. (2002). Narcissism and counterproductive work behaviors: Do bigger egos mean bigger problems? International Journal of Selection and Assessment, 10 (1/2), 126-134.

Pervin PhD, Lawrence A.; John PhD, Oliver P. (1999). Handbook of Personality: Theory and Research (2nd Edition). New York: Guilford Press. pp. 102-138.

Robinson, S.L., O'Leary-Kelly, A.M. (1998). Monkey see, monkey do: The influence of work groups on the antisocial behavior of employees. Academy of Management Journal, 41 (6), 658-673.

Rimfeld, K., Kovas, Y., Dale, P. S., \& Plomin, R. (2016). True Grit and Genetics: Predicting Academic Achievement From Personality. Journal of Personality and Social Psychology.

Smith, A., Organ D. W., \& Near J. (1983). Organizational citizenship behavior: Its nature and antecedents. Journal of Applied Psychology, 68(4), 653-663.

Spector, P. E., \& Fox, S. (2005). The Stressor - Emotion Model of Counterproductive Work Behaviour. Washington, DC, USA: American Psychological Association. pp. 151-174.

Spector, P. E., Fox, S., Penney, L. M., Bruursema, K., Goh, A., \& Kessler, S. (2006). The dimensionality of counterproductivity: Are all counterproductive behaviors created equal? Journal of Vocational Behavior, 68, 446460.
Sulea, C. (2008). Counterproductive behavior in organization. In E. Avram and C. Cooper (Eds.) Contemporary tendencies in Organizational - Managerial Psychology. Iași: Polirom.

Thompson, E.R. (2008). Development and Validation of an International English Big-Five Mini-Markers. Personality and Individual Differences 45(6), 542-548.

Tsai, W.-C., Chen, C.-C., \& Liu, H.-I. (2007). Test of a Model Linking Employee Positive Moods and Task Performance. Journal of Applied Psychology, 92(6), 1570-1583.

Van Dyne, L., \& LePine, J. A. (1998). Helping and voice extra-role behaviors: Evidence of construct and predictive validity. Academy of Management Journal, 41, 108-119.

Van Dyne, L., Cummings, L. L., \& Parks, J. M. 1995. Extra-role behaviors: In pursuit of construct and definitional clarity (A bridge over muddied waters). Greenwich, CT: JAI Press.

Williams, K. D., \& Karau, S. (1991). Social Loafing and Social Compensation: The Effects of Expectations of CoWorker Performance. Journal of Personality and Social Psychology, 61(4), 570-581.

Williams, L., \& Anderson, S. (1991). Job Satisfaction and Organizational Commitment as Predictors of Organizational Citizenship and In-Role Behaviors. Journal of Management, 17(3), 601-617.

Wong, C.-S., \& Law, K. S. (2002). The effects of leader and follower emotional intelligence on performance and attitude: An exploratory study. The Leadership Quarterly, 13, 243-274. 